\title{
Desenvolvimento vegetativo de pinhão-manso em diferentes arranjos de plantio em sistemas agrossilvipastoris
}

\author{
Marcelo Dias Müller(1), Domingos Sávio Campos Paciullo(1), Carlos Eugênio Martins ${ }^{(1)}$, \\ Wadson Sebastião Duarte da Rocha ${ }^{(1)}$ e Carlos Renato Tavares de Castro(1)

\begin{abstract}
(1)Embrapa Gado de Leite, Rua Eugênio do Nascimento, no 610, Dom Bosco, CEP 36038-330 Juiz de Fora, MG, Brasil. E-mail: marcelo.muller@embrapa.br, domingos.paciullo@embrapa.br, carlos.eugenio@embrapa.br, wadson.rocha@embrapa.br, carlos.castro@embrapa.br
\end{abstract}

Resumo - O objetivo deste trabalho foi avaliar o efeito de diferentes arranjos de plantio no desenvolvimento vegetativo de plantas de pinhão-manso estabelecidas em dois tipos de consórcio agrossilvipastoril. O experimento foi realizado no Município de Coronel Pacheco, MG, em delineamento de blocos ao acaso, em arranjo de parcelas subdivididas. A parcela foi representada por cinco espaçamentos: 6x3 m (555 plantas por hectare), 12x(2x2) m (714 plantas por hectare), 10x(2x2) m (833 plantas por hectare), 8x(2x2) m (1.000 plantas por hectare) e 6x1,5 m (1.111 plantas por hectare); e a subparcela, por dois tipos de consórcio: agrossilvipastoril (integração lavoura-pecuária-pinhão-manso) e silvipastoril (integração pecuária-pinhão-manso). As avalições foram realizadas nas safras 2010/2011 e 2011/2012. O espaçamento de plantio de 6x3 m proporcionou maior desenvolvimento em diâmetro de copa e número de brotações das plantas de pinhão-manso, na safra 2010/2011. Na safra 2011/2012, foi observado maior desenvolvimento em altura com o espaçamento de plantio de $8 \times(2 \times 2) \mathrm{m}$. O consórcio de pinhão-manso $\mathrm{x}$ milho $\mathrm{x}$ pastagem proporciona maior desenvolvimento das plantas de pinhão-manso para todas as variáveis estudadas nas duas safras.

Termos para indexação: Jatropha curcas, agrossilvicultura, biodiesel, densidades de plantio, integração lavoura-pecuária-floresta.

\section{Physic nut vegetative growth in different agrosilvopastoral system planting arrangements}

\begin{abstract}
The objective of this work was to evaluate the effect of different planting arrangements on the vegetative growth of physic nut trees established in two agrosilvopastoral intercropping systems. The experiment was carried out in the municipality of Coronel Pacheco, in the state of Minas Gerais, Brazil, in a randomized complete block design, in a split-plot arrangement. The experimental unit was represented by five

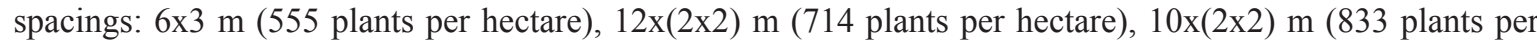
hectare), $8 \times(2 \times 2) \mathrm{m}(1,000$ plants per hectare), and $6 \times 1.5 \mathrm{~m}$ (1,111 plants per hectare); and the subplot, by two intercropping systems: agrossilvopastoral (crop-livestock-forestry) and silvopastoral (livestock-forestry). The evaluations were carried out during the 2010/2011 and 2011/2012 harvest seasons. The plant spacing of 6x3 m provided higher crown diameter and number of shoots of physic nut plants in the 2010/2011 harvest season. In the 2011/2012 harvest season, a higher height growth was observed with the $8 \times(2 \times 2) \mathrm{m}$ plant spacing. The physic nut $\mathrm{x}$ corn $\mathrm{x}$ forage intercropping system provides higher physic nut plant growth for all studied variables in both harvest seasons.
\end{abstract}

Index terms: Jatropha curcas, agrisilviculture, biodiesel, planting densities, crop-livestock-forestry integration.

\section{Introdução}

O pinhão-manso (Jatropha curcas L.) é uma espécie oleaginosa pertencente à família Euphorbiaceae com grande potencial para produção de óleo. Além disso, por ser uma espécie arbustiva, perene e de crescimento rápido, pode ser estabelecida em sistemas de consórcio com outras espécies (Achten et al., 2008). Portanto, ao se levar em consideração que o seu cultivo leva em torno de quatro anos para atingir o máximo da produção (Saturnino et al., 2005), a consorciação com outras atividades pode ser alternativa viável, principalmente para a agricultura familiar.

A consorciação de espécies arbóreas ou arbustivas com outras culturas, notadamente com pastagens e criação animal, em sistemas agrossilvipastoris, traz uma série de benefícios, tanto produtivos quanto ambientais, na medida em que representa a otimização 
do uso do solo. O uso da técnica de plantio direto na palha, bem como a introdução de um componente arbóreo/arbustivo, proporciona aporte de matéria orgânica, o que conduz a melhorias nos atributos físicos, químicos e biológicos do solo (Neves et al., 2009; Salton et al., 2013). De modo semelhante, Xavier et al. (2014) observaram maior tendência de deposição de serapilheira e, consequentemente, de nitrogênio em sistemas silvipastoris, em comparação ao monocultivo de braquiária. Os mesmos autores ainda relataram maiores ganhos de peso por animal no sistema silvipastoril. O efeito positivo de sistemas silvipastoris na qualidade da forragem e no aumento de ganho de peso em novilhas leiteiras foi descrito por Paciullo et al. (2011). A presença de um componente arbóreo também oferece a possibilidade de aumento do conforto térmico para os animais (Leme et al., 2005), o pode contribuir para o aumento da produtividade animal.

Assim, conclui-se que a introdução do pinhão-manso nesses sistemas pode ser acompanhada dos mesmos benefícios. Entretanto, estudos nessa área ainda são incipientes, com destaque para os realizados por Silva et al. (2012a), que analisaram o crescimento de espécies forrageiras consorciadas com o pinhão-manso, e por Schulz et al. (2014), que estudaram o desenvolvimento de plantas de pinhão-manso estabelecidas em consórcio com Tifton 85 , com diferentes quantidades de área útil por planta até os 18 meses de idade.

Cabe ressaltar que o cultivo associado de diferentes espécies de plantas em uma mesma área pressupõe a existência de interações dinâmicas e que se alteram com o tempo, principalmente em áreas onde há o componente arbóreo/arbustivo, tendo em vista o crescimento contínuo em altura, a projeção de copa e o índice de área foliar, que modificam a distribuição dos recursos ao longo do tempo. Dessa forma, a produtividade do sistema será modificada continuamente (José et al., 2004). Nesse sentido, o estudo do desenvolvimento vegetativo de plantas lenhosas componentes de sistemas consorciados, em diferentes arranjos de plantio e tipos de consórcio, é fundamental para o direcionamento de práticas de manejo, tais como definição de espaçamento entre plantas e arranjo de plantio. Além disso, a otimização de várias atividades em uma mesma unidade produtiva pode trazer benefícios socioeconômicos, como diversificação da produção e da renda (Müller et al., 2011).
O objetivo deste trabalho foi avaliar o efeito de diferentes arranjos de plantio no desenvolvimento vegetativo de plantas de pinhão-manso estabelecidas em dois tipos de consórcio agrossilvipastoril.

\section{Material e Métodos}

O experimento foi implantado em janeiro de 2009 em uma área de 2,4 ha de pastagem de Urochloa decumbens (Syn. Brachiaria brizantha) 'Basilisk', já estabelecida no Campo Experimental José Henrique Bruschi, pertencente à Embrapa Gado de Leite, no Município de Coronel Pacheco, MG (2133'22"S, $\left.43^{\circ} 06^{\prime} 15^{\prime \prime} \mathrm{W}\right)$. O solo é classificado como Latossolo Vermelho-Amarelo distrófico, localizado em área montanhosa da região da Zona da Mata do Estado de Minas Gerais, com a seguinte caracterização química: $\mathrm{pH}$ em $\mathrm{H}_{2} \mathrm{O}$ de 5,$21 ; 2,16 \mathrm{mg} \mathrm{dm}^{-3}$ de $\mathrm{P} ; 64,6 \mathrm{mg}$ $\mathrm{dm}^{-3}$ de K $\mathrm{K}^{+} ; 1,09 \mathrm{cmol}_{\mathrm{c}} \mathrm{dm}^{-3} \mathrm{de} \mathrm{Ca}^{2+} ; 0,76 \mathrm{cmol}_{\mathrm{c}} \mathrm{dm}^{-3}$ de $\mathrm{Mg}^{2+} ; 0,28 \mathrm{cmol}_{\mathrm{c}} \mathrm{dm}^{-3}$ de $\mathrm{Al}^{3+} ; 3,75 \mathrm{cmol}_{\mathrm{c}} \mathrm{dm}^{-3}$ de $\mathrm{H}^{+}+\mathrm{Al}^{3+}$; soma de bases de 2,01 $\mathrm{cmol}_{\mathrm{c}} \mathrm{dm}^{-3} ; \mathrm{CTC}_{(\mathrm{t})}$ de $2,29 \mathrm{cmol}_{\mathrm{c}} \mathrm{dm}^{-3} ; \mathrm{CTC}_{(\mathrm{T})}$ de $5,76 \mathrm{cmol}_{\mathrm{c}} \mathrm{dm}^{-3} ; \mathrm{m}$ de $15 \%$; $\mathrm{V}$ de $34,48 \%$; 2,46 dag $\mathrm{kg}^{-1}$ de MO; 32,58 $\mathrm{mg} \mathrm{L}^{-1}$ de P remanescente; $331,8 \mathrm{~g} \mathrm{~kg}^{-1}$ de areia grossa; $290,3 \mathrm{~g} \mathrm{~kg}^{-1}$ de areia fina; $122,1 \mathrm{~g} \mathrm{~kg}^{-1}$ de silte; e $255,9 \mathrm{~g} \mathrm{~kg}^{-1}$ de argila.

O clima da região é do tipo Cwa, segundo Köppen, mesotérmico, com verão quente e chuvoso e inverno frio e seco. A pluviosidade média anual é de aproximadamente $1.500 \mathrm{~mm}$, distribuídos irregularmente, e somente $13 \%$ desse total ocorre de maio a setembro, período considerado como época da seca. A temperatura média anual é de $18^{\circ} \mathrm{C}$ nos meses mais frios e de $22^{\circ} \mathrm{C}$ no verão (Figura 1).

Utilizou-se o delineamento de blocos ao acaso, em arranjo de parcelas subdivididas, com três repetições. A parcela foi representada por cinco espaçamentos (Figura 2): $6 \times 3 \mathrm{~m}$ (555 plantas por hectare), $12 \times(2 \times 2) \mathrm{m}$ (714 plantas por hectare), 10x(2x2) $\mathrm{m}$ (833 plantas por hectare), $8 \times(2 \times 2) \mathrm{m}$ (1.000 plantas por hectare) e $6 \times 1,5 \mathrm{~m}$ (1.111 plantas por hectare); e a subparcela, por dois tipos de consórcio: agrossilvipastoril - SASP (integração lavourapecuária-pinhão manso) e silvipastoril - SSP (integração pecuária-pinhão manso). Os espaçamentos $6 \times 3$ e 6x1,5 m são constituídos por renques formados por uma linha simples de plantas, com espaçamento entre renques de $6 \mathrm{~m}$. Os espaçamentos $8 \times(2 \times 2), 10 \times(2 \times 2)$ e $12 \times(2 \times 2) \mathrm{m}$ são constituídos por renques formados por duas linhas de plantas de pinhão-manso, e, em cada renque, as linhas de 
plantas são espaçadas entre si em $2 \mathrm{~m}$. Em cada linha, as plantas também são espaçadas em $2 \mathrm{~m}$. O espaçamento entre renques variou de 8 a $12 \mathrm{~m}$.

Os tratamentos com linhas simples (6x3 e 6x1,5 m) foram compostos por quatro linhas de plantio e nove plantas em cada linha. Aárea útil da parcela foi definida como as duas linhas centrais, tendo-se utilizado cinco plantas em cada linha. Os demais tratamentos, com linhas duplas, foram compostos por três faixas de duas linhas, com nove plantas em cada linha. A área útil da parcela foi definida pelas duas linhas da faixa central, tendo-se utilizado cinco plantas em cada linha.

Inicialmente, foi feita a dessecação do pasto, com uso de $3 \mathrm{~L} \mathrm{ha}^{-1}$ de glifosato. O sistema de SASP foi caracterizado pela semeadura do milho (Zea mays L.) 'AG 1051' entre as faixas de pinhão-manso, sobre palhada de $U$. decumbens, em espaçamento de $1 \mathrm{~m}$ entre fileiras, tendo-se deixado $1 \mathrm{~m}$ de distância das plantas de pinhão-manso. Para a adubação do milho, foram utilizados $350 \mathrm{~kg} \mathrm{ha}^{-1}$ da fórmula N-P-K 08-28-16 no plantio e $300 \mathrm{~kg} \mathrm{ha}^{-1}$ da fórmula N-P-K 20-05-20 em cobertura, divididos em duas aplicações anuais, em que metade foi aplicada no início da época chuvosa (novembro) e a outra metade no final (fevereiro/março), conforme a recomendação de adubação baseada na análise do solo. O sistema SSP foi caracterizado pela implantação do pinhão-manso na pastagem já estabelecida, sem adubação da pastagem.

O pasto foi manejado em sistema de pastejo rotativo, com períodos de ocupação que variaram entre cinco e sete dias e período de descanso entre 35 e 49 dias, de acordo com a época do ano (período chuvoso e seco, respectivamente). Foram usadas novilhas Holandês $\mathrm{x}$ Zebu, com peso vivo médio inicial de $200 \mathrm{~kg}$. A taxa de lotação apresentou valores extremos de 0,66 UA $\mathrm{ha}^{-1}$ na época seca e de 1,6 $\mathrm{UA} \mathrm{ha}^{-1}$ na época chuvosa. Anualmente, o lote de novilhas era substituído por outro de peso vivo inicial semelhante.

Tendo em vista que a implantação do experimento se deu no início de 2009, o plantio do milho nas entrelinhas do pinhão-manso foi realizado somente na safra seguinte (2009/2010), tendo sido repetido nas duas próximas safras (2010/2011 e 2011/2012).

Para a implantação do pinhão-manso, foram utilizadas mudas propagadas por sementes com 45 dias de idade, plantadas em covas de 30x30x30 cm, abertas com motocoveadeira. A adubação de plantio

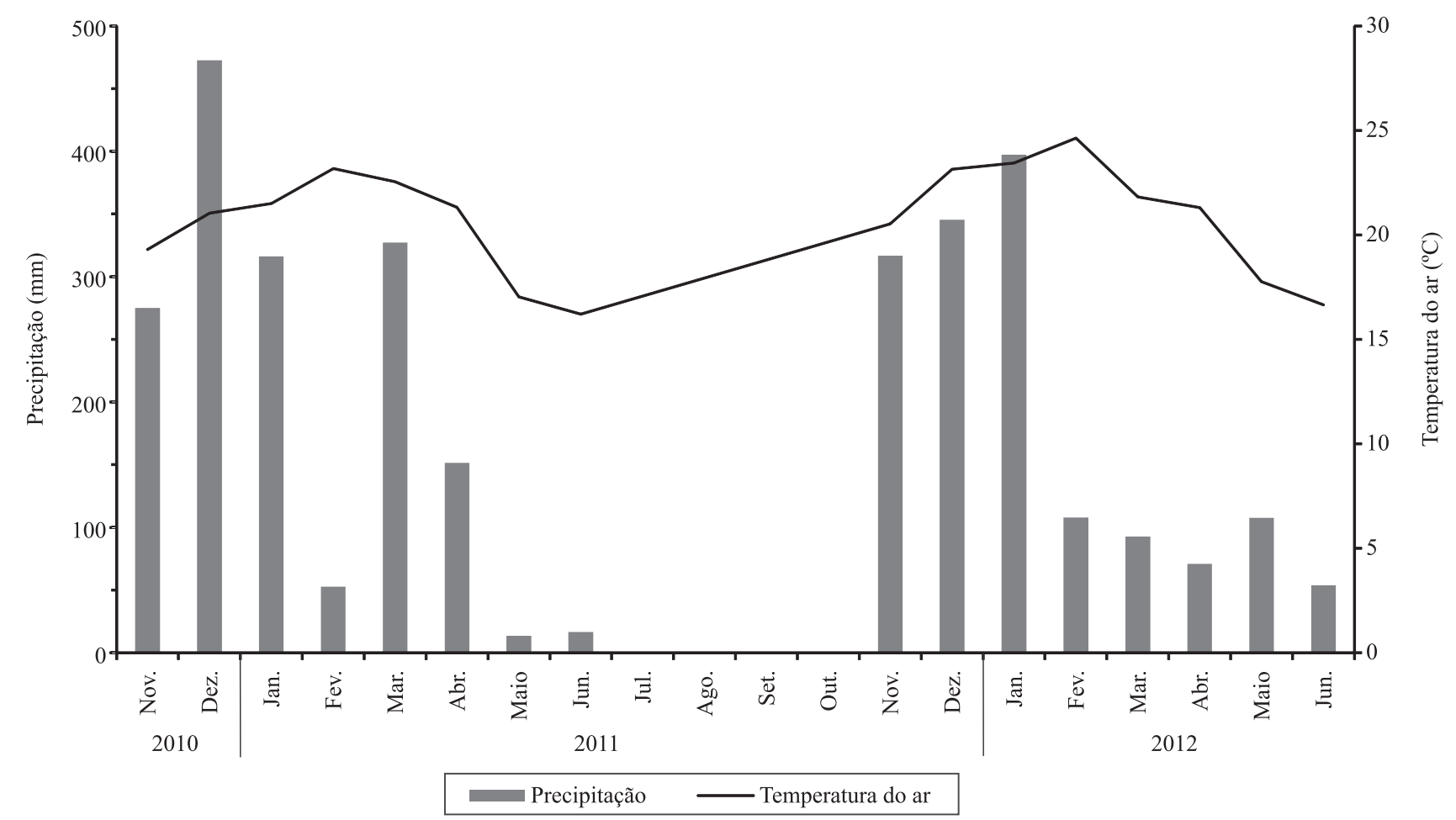

Figura 1. Precipitação mensal e temperatura média do ar, em Coronel Pacheco, MG, durante o período experimental. Dados obtidos na estação climatológica do Instituto Nacional de Meteorologia (Inmet), na Universidade Federal de Juiz de Fora, MG. 
correspondeu a $200 \mathrm{~g}$ por cova da fórmula N-P-K 08-28-16 no plantio e a $150 \mathrm{~g}$ por cova da fórmula N-P-K 20-05-20, divididos em duas aplicações anuais: metade aplicada no início da época chuvosa (novembro) e a outra metade no final (final de fevereiro). Nas safras seguintes (2009/2010, 2010/2011 e 2011/2012), foi utilizada a mesma formulação aplicada manualmente, a lanço, em superfície, na projeção da copa, com
$6 \times 1,5 \mathrm{~m}-1.111$ plantas por ha

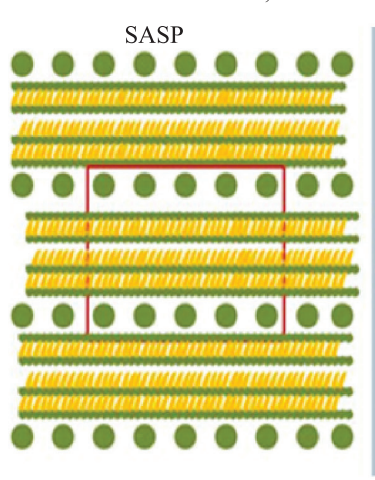

SSP

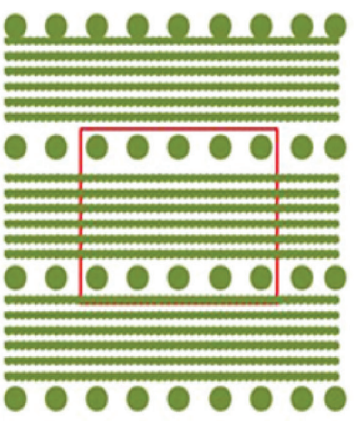

$10 \times(2 \times 2) m-833$ plantas por ha

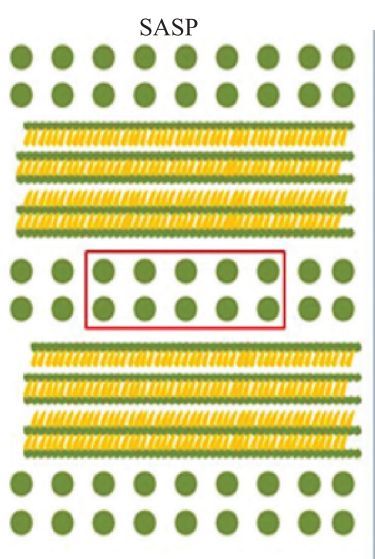

SSP

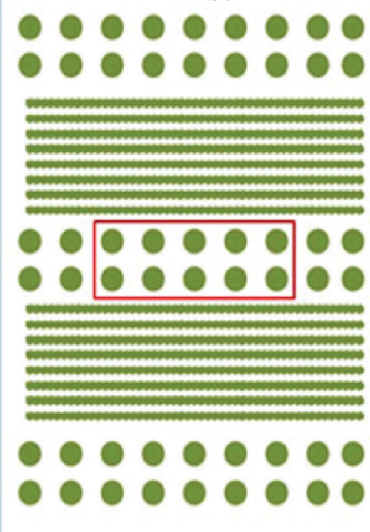

$6 \times 3 \mathrm{~m}-555$ plantas por ha

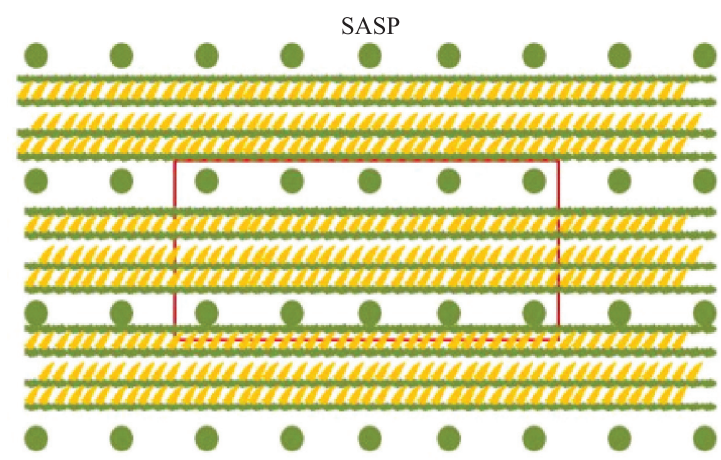

$8 \times(2 \times 2) m-1.000$ plantas por ha

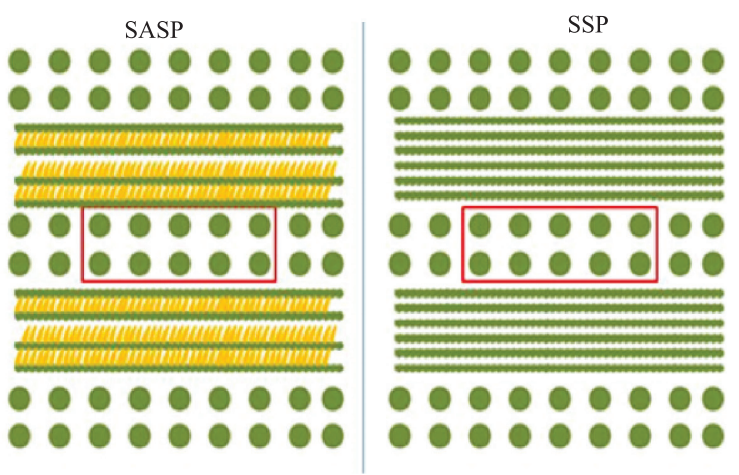

$12 \times(2 \times 2) m-714$ plantas por ha SASP

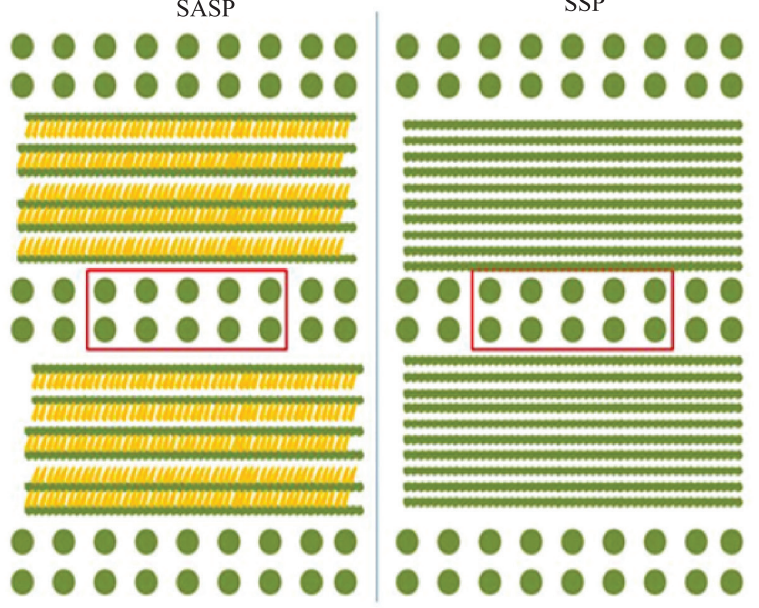

$6 \times 3 \mathrm{~m}-555$ plantas por ha SSP

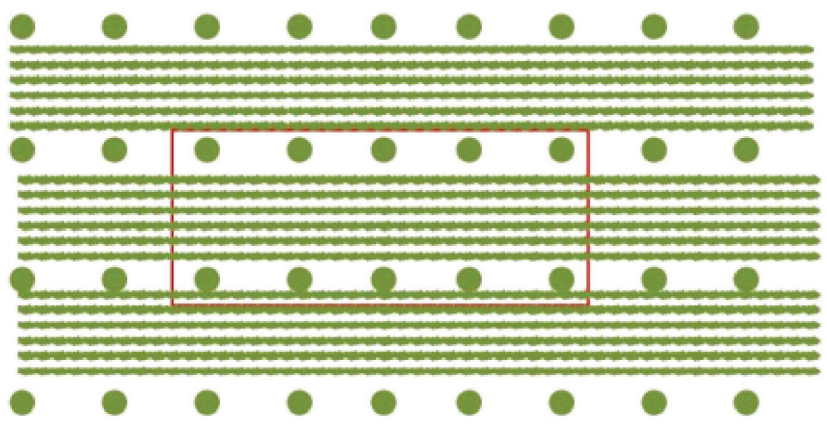

Figura 2. Arranjo ilustrativo das unidades experimentais de plantio de pinhão-manso (Jatropha curcas). Para cada espaçamento de plantio, são apresentadas duas subparcelas: SASP, sistema agrossilvipastoril (integração lavoura-pecuária-pinhão-manso); SSP, sistema silvipastoril (integração pecuária-pinhão-manso). Os círculos correspondem às plantas de pinhão-manso. As linhas verdes correspondem à braquiária, e o tracejado amarelo corresponde ao milho. O retângulo no centro das parcelas corresponde à parcela útil, onde foram tomadas as medidas das plantas de pinhão-manso. 
doses crescentes de 200, 300 e 375 g por planta, respectivamente, segundo Dias et al. (2007).

O controle de plantas daninhas nas linhas de pinhão-manso, após o plantio, foi realizado com uso de glifosato, na dose de $1.080 \mathrm{~g} \mathrm{ha}^{-1}$ de e.a., aplicado com pulverizador, com pressão constante de $2 \mathrm{kgf} \mathrm{cm}^{-2}$ e volume de pulverização de $150 \mathrm{~L} \mathrm{ha}^{-1}$. Para evitar injúrias do herbicida às plantas de pinhão-manso, utilizou-se barra de pulverização com dois bicos antideriva AVI 110.015, distanciados de 0,5 m.

$\mathrm{Na}$ safra 2011/2012, ao final da época seca, foi realizada uma poda de produção à altura de $1,8 \mathrm{~m}$ do solo em todas as parcelas, para estimular a formação de novas brotações e aumentar a produtividade (Oliveira et al., 2010), bem como concentrar o ciclo de produção (Silva et al., 2012b).

Para a avaliação do desempenho das plantas de pinhão-manso, foram utilizados alguns descritores agronômicos comumente empregados na identificação dessa espécie: altura das plantas, com auxílio de régua telescópica com $450 \mathrm{~cm}$ de comprimento, posta paralelamente ao caule da planta avaliada, com a extremidade inferior apoiada no solo, tendo-se medido a altura do ápice do ramo principal; diâmetro de copa, representado pela média de duas medidas tomadas em direções ortogonais à altura de $1,30 \mathrm{~m}$ do solo; e número total de novas brotações. Foram utilizadas dez plantas úteis por parcela, independentemente do espaçamento. As medições foram feitas mensalmente.

Os dados foram submetidos à análise de variância, e, quando necessário, as médias foram comparadas pelo teste de Scott \& Knott, a 5\% de probabilidade. Para tanto, foi utilizado o programa Sisvar (Ferreira, 2011).

\section{Resultados e Discussão}

Foram observados efeitos apenas no nível de subparcela (tipo de consórcio) para as variáveis altura de planta, diâmetro de copa e número de brotações, na safra 2010/2011 (Tabela 1). O sistema pinhão-manso x milho x pastagem (SASP) apresentou valores médios maiores para diâmetro de copa (3 m), comparado ao sistema SSP (2,74 m). Na safra seguinte (2011/2012), já havia sido observado efeito de parcela, em que os espaçamentos $6 \times 3$ e 6x1,5 m apresentaram as maiores médias para a variável altura, tendo diferido das demais. $\mathrm{O}$ diâmetro de copa foi superior apenas para o espaçamento $6 \times 3 \mathrm{~m}$. No entanto, a variável número de brotações sofreu influência tanto do espaçamento de plantio quanto do tipo de consórcio, na safra 2010/2011. $\mathrm{O}$ espaçamento $6 \times 3 \mathrm{~m}$ proporcionou maior número de brotações, tendo diferido dos demais tratamentos. $\mathrm{Da}$ mesma forma, o sistema SASP favoreceu o desenvolvimento de brotações e o diâmetro de copa.

No desdobramento da interação entre espaçamento e tipo de consórcio, as variáveis diâmetro de copa e número de brotações foram influenciadas pelo espaçamento de plantio, principalmente no sistema SASP (Tabela 2). Não foi observado efeito do espaçamento de plantio na variável altura, dentro do tipo de consórcio. O maior desenvolvimento vegetativo das plantas de pinhão-manso, estabelecidas em espaçamentos maiores, pode ser atribuído ao maior espaço disponível para as plantas aproveitarem os recursos do solo e a luminosidade incidente. Mesmo no caso do espaçamento $6 \times 1,5 \mathrm{~m}$ que corresponde à maior densidade de plantio (1.111 plantas por hectare), apesar da maior competição entre plantas na linha de plantio (1,5 m entre plantas), há maior espaço entre as linhas.

Entretanto, vale destacar que a integração de árvores/arbustos com cultivos agrícolas e pastagens pode resultar em um uso mais eficiente da radiação incidente, da água e dos nutrientes no solo, uma vez que, por meio de suas diferentes arquiteturas biológicas, as plantas exploram diferentes porções da atmosfera e do solo (Macdicken \& Vergara, 1990). Essa hipótese foi confirmada por Lehmann et al. (1998) e Odhiambo et al. (2001), que verificaram que o uso da água no sistema agrossilvipastoril foi mais eficiente que nos cultivos solteiros. Esse resultado é indicativo de que espécies arbóreas e agrícolas, quando em consórcio, exploram diferentes partes do perfil do solo, em que a espécie arbórea apresenta maior densidade de raízes nas partes mais profundas do solo e a espécie agrícola, maior densidade de raízes na superfície. No presente trabalho, isso pode explicar a superioridade do desenvolvimento vegetativo das plantas estabelecidas no sistema de integração lavoura-pecuária-pinhão-manso. Com a introdução do milho, esse efeito pode ser atribuído ao aproveitamento do adubo residual da cultura pelas plantas de pinhão-manso.

Severino et al. (2006) e Bizinoto et al. (2010) não encontraram efeito da densidade de plantas para altura de planta de mamona (Ricinus communis L.), estabelecidas em diferentes espaçamentos de 
plantio. Contudo, Carvalho et al. (2010) relataram que, dependendo da cultivar utilizada, a densidade populacional pode influenciar a altura da mamoneira.

O espaçamento $6 \times 3 \mathrm{~m}$, no sistema SASP, favoreceu o maior desenvolvimento em diâmetro de copa $(3,44 \mathrm{~m})$, seguido pelo espaçamento $8 \times(2 \times 2) \mathrm{m}(3,12 \mathrm{~m})$, na safra $2010 / 2011$. Os demais tratamentos não diferiram entre si. $\mathrm{Na}$ safra seguinte, somente o espaçamento $6 \times 3 \mathrm{~m}$ diferiu dos demais, com média superior de 5,22 m. No sistema SSP, foi observado efeito somente para altura de planta e diâmetro de copa, na safra 2011/2012. Os espaçamentos $6 \times 1,5$ e $6 \times 3 \mathrm{~m}$ proporcionaram os maiores valores para altura de planta, e o espaçamento $6 \times 3 \mathrm{~m}$ promoveu maior diâmetro de copa, de 4,31 m (Tabela 2).

Não houve efeito de espaçamento no número de brotações, no sistema SSP. No sistema SASP, o espaçamento $6 \times 3 \mathrm{~m}$ apresentou os maiores valores para a variável, tendo diferido dos demais tratamentos nas duas safras (50,47 e 86,97, respectivamente).

Horschutz et al. (2012) constataram efeito de espaçamento de plantio em plantas de pinhão-manso aos 480 dias após o plantio e que espaçamentos menos adensados apresentaram maiores áreas foliares por planta. Isso representa maior capacidade das plantas em aproveitar a energia solar, o que pode explicar o maior crescimento de plantas estabelecidas em espaçamentos mais amplos (González-Sanpedro et al., 2008). Porém, há um limite máximo de plantas em um determinado espaço, em razão da competição fisiológica entre elas (Chavarria et al., 2011). Singh et al. (2013) não relataram efeitos do aumento de densidade de plantio nas variáveis altura e número de brotações de plantas

Tabela 1. Altura de planta (m), diâmetro de copa $(\mathrm{m})$ e número de brotações de plantas de pinhão-manso (Jatropha curcas) estabelecidas em diferentes espaçamentos e tipos de consórcio, nas safras 2010/2011 e 2011/2012(1).

\begin{tabular}{|c|c|c|c|c|c|c|c|}
\hline \multirow{2}{*}{$\begin{array}{l}\text { Espaçamento } \\
\text { (m) }\end{array}$} & \multirow{2}{*}{$\begin{array}{c}\text { Densidade } \\
\text { (plantas por hectare) }\end{array}$} & \multicolumn{3}{|c|}{ Safra 2010/2011 } & \multicolumn{3}{|c|}{ Safra $2011 / 2012$} \\
\hline & & Altura de planta & Diâmetro de copa & № de brotações & Altura de planta & Diâmetro de copa & № de brotações \\
\hline $6 \times 1,5$ & 1.111 & $2,97 \mathrm{a}$ & $2,77 \mathrm{a}$ & $25,31 \mathrm{~b}$ & $4,33 \mathrm{a}$ & $3,49 \mathrm{~b}$ & $59,27 \mathrm{a}$ \\
\hline $8 \times(2 \times 2)$ & 1.000 & $2,92 \mathrm{a}$ & $2,85 \mathrm{a}$ & $28,95 b$ & $3,93 b$ & $3,26 b$ & $52,49 a$ \\
\hline $10 \times(2 \times 2)$ & 833 & $2,81 \mathrm{a}$ & $2,66 \mathrm{a}$ & $25,98 b$ & $3,78 b$ & $3,07 \mathrm{~b}$ & $45,22 \mathrm{a}$ \\
\hline $12 \times(2 \times 2)$ & 714 & $2,86 a$ & $2,65 a$ & $24,52 b$ & $3,85 b$ & $3,04 b$ & $40,75 a$ \\
\hline $6 \times 3$ & 555 & $2,82 \mathrm{a}$ & $3,14 \mathrm{a}$ & $37,63 \mathrm{a}$ & $4,23 \mathrm{a}$ & $4,77 \mathrm{a}$ & $67,18 \mathrm{a}$ \\
\hline \multicolumn{8}{|l|}{ Consórcio $^{(2)}$} \\
\hline SASP & & $3,00 \mathrm{a}$ & $3,01 \mathrm{a}$ & $35,78 \mathrm{a}$ & $4,20 \mathrm{a}$ & $3,77 \mathrm{a}$ & $65,24 a$ \\
\hline SSP & & $2,74 b$ & $2,61 b$ & $21,18 b$ & $3,85 b$ & $3,28 b$ & $40,72 b$ \\
\hline
\end{tabular}

${ }^{(1)}$ Médias seguidas de letras iguais, nas colunas, não diferem pelo teste de Scott \& Knott, a 5\% de probabilidade. (2)SASP, sistema agrossilvipastoril (integração lavoura-pecuária-pinhão-manso); SSP, sistema silvipastoril (integração pecuária-pinhão-manso).

Tabela 2. Altura de planta (m), diâmetro de copa (m) e número de brotações de plantas de pinhão-manso (Jatropha curcas), com efeitos desdobrados dentro de cada nível de subparcela (sistema de consórcio), nas safras 2010/2011 e 2011/2012 ${ }^{(1)}$.

\begin{tabular}{|c|c|c|c|c|c|c|}
\hline \multirow{2}{*}{$\begin{array}{l}\text { Espaçamento } \\
\text { (m) }\end{array}$} & \multicolumn{3}{|c|}{ Safra 2010/2011 } & \multicolumn{3}{|c|}{ Safra 2011/2012 } \\
\hline & Altura de planta & Diâmetro de copa & № de brotações & Altura de planta & Diâmetro de copa & № de brotações \\
\hline \multicolumn{7}{|c|}{ Consórcio SASP } \\
\hline $6 \times 3$ & $2,93 \mathrm{a}$ & $3,44 \mathrm{a}$ & $50,47 \mathrm{a}$ & $4,35 \mathrm{a}$ & $5,22 \mathrm{a}$ & $86,79 a$ \\
\hline $8 x(2 \times 2)$ & $3,12 \mathrm{a}$ & $3,12 b$ & $36,50 \mathrm{~b}$ & $4,20 \mathrm{a}$ & $3,56 b$ & $66,73 b$ \\
\hline $10 \times(2 \times 2)$ & $2,97 \mathrm{a}$ & $2,84 \mathrm{c}$ & $34,10 \mathrm{~b}$ & $4,00 \mathrm{a}$ & $3,28 b$ & $58,51 \mathrm{~b}$ \\
\hline $12 \times(2 \times 2)$ & $3,00 \mathrm{a}$ & $2,72 \mathrm{c}$ & $28,60 \mathrm{~b}$ & $4,04 \mathrm{a}$ & $3,12 b$ & $46,93 b$ \\
\hline $6 \times 1,5$ & $3,03 \mathrm{a}$ & $2,93 \mathrm{c}$ & $29,23 \mathrm{~b}$ & $4,40 \mathrm{a}$ & $3,67 \mathrm{~b}$ & $67,25 \mathrm{~b}$ \\
\hline \multicolumn{7}{|c|}{ Consórcio SSP } \\
\hline $6 \times 3$ & $2,74 \mathrm{a}$ & $2,83 \mathrm{a}$ & $24,79 a$ & $4,11 \mathrm{a}$ & $4,31 \mathrm{a}$ & $47,56 \mathrm{a}$ \\
\hline $8 x(2 \times 2)$ & $2,72 \mathrm{a}$ & $2,57 \mathrm{a}$ & $21,40 \mathrm{a}$ & $3,66 b$ & $2,96 b$ & $38,25 \mathrm{a}$ \\
\hline $10 \times(2 \times 2)$ & $2,64 a$ & $2,47 \mathrm{a}$ & $17,87 \mathrm{a}$ & $3,56 \mathrm{~b}$ & $2,85 b$ & $31,93 a$ \\
\hline $12 \times(2 \times 2)$ & $2,71 \mathrm{a}$ & $2,58 \mathrm{a}$ & $20,44 a$ & $3,66 b$ & $2,97 b$ & $34,57 \mathrm{a}$ \\
\hline $6 \times 1,5$ & $2,90 \mathrm{a}$ & $2,61 \mathrm{a}$ & $21,39 \mathrm{a}$ & $4,25 \mathrm{a}$ & $3,31 \mathrm{~b}$ & $51,29 \mathrm{a}$ \\
\hline
\end{tabular}

${ }^{(1)}$ Médias seguidas de letras iguais não diferem pelo teste de Scott \& Knott, a 5\% de probabilidade. SASP, sistema agrossilvipastoril (integração lavoura-pecuária-pinhão-manso); SSP, sistema silvipastoril (integração pecuária-pinhão-manso). 
de pinhão-manso, em quatro localidades, na Índia. Segundo os autores, mesmo o menor espaçamento entre plantas avaliado, de $2 \times 2 \mathrm{~m}$, não foi suficiente para que o efeito de competição pudesse ser observado. Comportamento semelhante também foi descrito para outras espécies vegetais, por Bizinoto et al. (2010) e Soratto et al. (2011), em mamona; Bezerra et al. (2009), em feijão-caupi [Vigna unguiculata (L.) Walp.]; e Pereira et al. (2011), em café (Coffea arabica L.). De acordo com os autores, isso se deve a maior área para captação de luz nos maiores espaçamentos, o que possibilita uma arquitetura de copa produtiva mais adequada e, consequentemente, maior produção de massa de matéria seca e maior expressão do potencial de emissão de racemos pelas plantas.

$\mathrm{O}$ efeito do tipo de consórcio dentro de cada espaçamento evidencia que, em sistema SASP, há maior desenvolvimento vegetativo das plantas (Figura 3). Para a variável altura de planta, não houve efeito significativo do tipo de consórcio nos espaçamentos $6 \times 3$ e $6 \times 1,5 \mathrm{~m}$, na safra 2010/2011, e $6 \times 3,12 \times(2 \times 2)$ e $6 \times 1,5 \mathrm{~m}$ na safra 2011/2012. Apesar disso, os valores
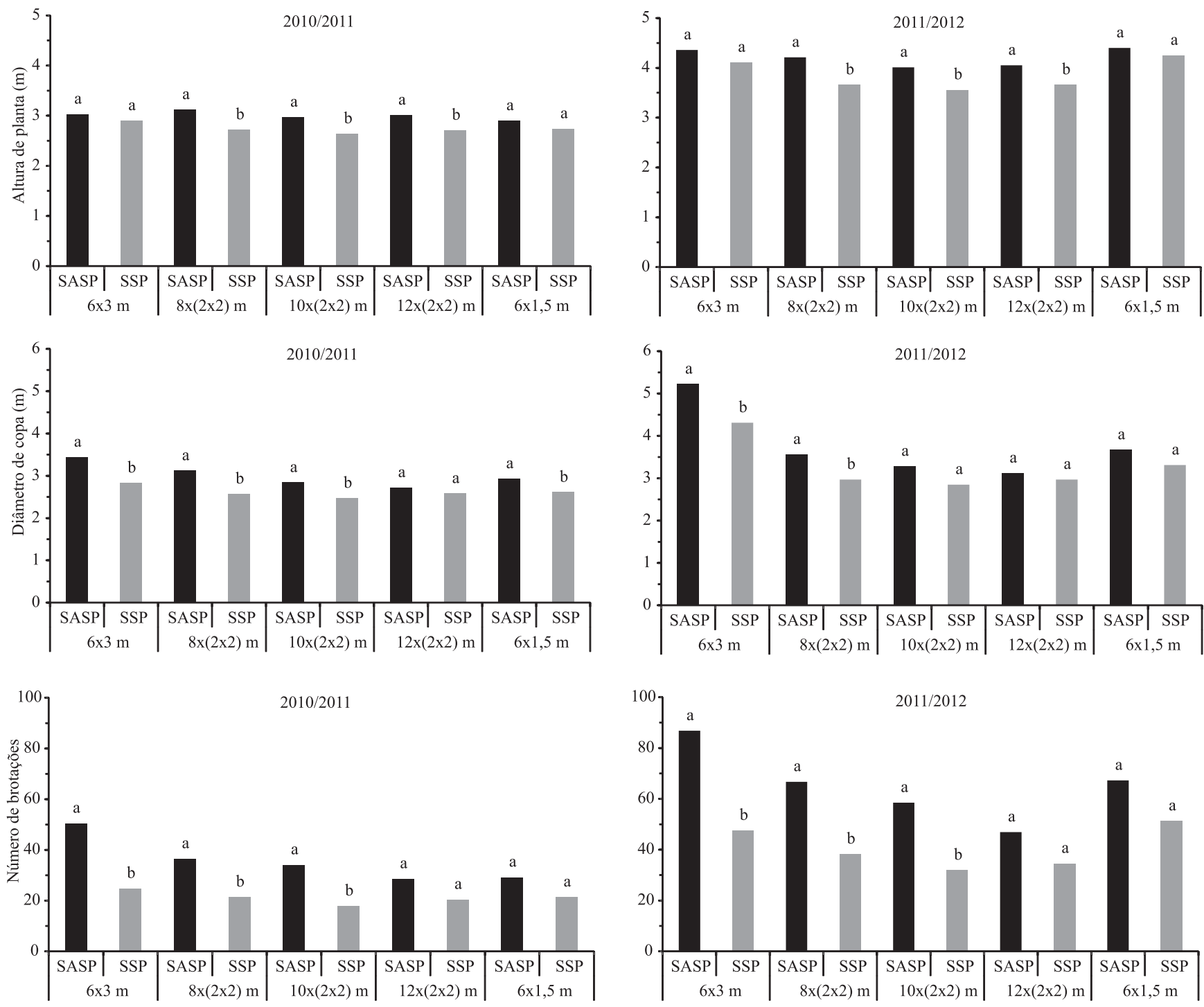

Figura 3. Efeito do tipo de consórcio na altura de planta, no diâmetro de copa e no número de brotações de plantas de pinhão-manso (Jatropha curcas) estabelecidas em diferentes espaçamentos de plantio, nas safras 2010/2011 e 2011/2012. Médias seguidas de letras iguais não diferem pelo teste de Scott \& Knott, a 5\% de probabilidade. SASP, sistema agrossilvipastoril (integração lavoura-pecuária-pinhão-manso); SSP, sistema silvipastoril (integração pecuária-pinhão-manso). 
de altura foram maiores no sistema SASP. Para os demais tratamentos, nas duas safras, o sistema SASP apresentou valores superiores aos do SSP.

Comportamento similar foi observado para as variáveis diâmetro de copa e número de brotações. Na safra 2010/2011, o sistema SASP não apresentou efeito apenas para o espaçamento $12 \mathrm{x}(2 \mathrm{x} 2) \mathrm{m}$. O número de brotações foi superior para os espaçamentos $6 \times 3$, $8 \times(2 \times 2)$ e $10 \times(2 \times 2) \mathrm{m}$. Para os demais, não houve efeito significativo, apesar dos maiores valores observados no sistema SASP. Na safra seguinte, o sistema SASP proporcionou maiores valores de diâmetro de copa apenas para os espaçamentos $6 \times 3$ e $8 \times(2 \times 2) \mathrm{m}$. Para o número de brotações, além dos espaçamentos $6 \times 3$ e $8 \times(2 \times 2) \mathrm{m}$, também foi verificada superioridade do sistema SASP em relação ao SSP no espaçamento $10 \times(2 \times 2) \mathrm{m}$.

Souza Junior et al. (2012) obtiveram resultados semelhantes para cultivares de mamona em consórcio com gergelim (Sesamum indicum L.) e feijão-caupi, no Semiárido nordestino. O consórcio com feijão-caupi proporcionou maiores rendimentos e maiores valores de diâmetros caulinares, em comparação ao monocultivo da mamona. De acordo com os autores, esse resultado pode ser explicado pelo fato de o feijão-caupi ter sido semeado após o plantio da mamona, o que teria diminuído a competição interespecífica. Além disso, o feijão-caupi é uma leguminosa fixadora de nitrogênio, o que poderia ter contribuído para o melhor desempenho do consórcio.

É importante destacar que os resultados obtidos devem ser analisados com cautela, uma vez que mostram apenas os efeitos dos tratamentos na produção do pinhão-manso e, portanto, não representam $\mathrm{o}$ sistema como um todo. Assim, para a recomendação do estabelecimento de plantas de pinhão-manso em sistemas consorciados, devem ser estudados os efeitos dos arranjos de plantio de pinhão-manso nas culturas intercalares e as suas interações. Silva et al. (2012a) avaliaram o crescimento e a produção de espécies forrageiras consorciadas com pinhão-manso, e observaram que o espaçamento utilizado, de $3 \times 2 \mathrm{~m}$, não corresponde a um espaçamento ideal para sistemas consorciados, tendo em vista a grande ocupação do sítio pelas plantas de pinhão-manso. Além disso, são necessários trabalhos relativos ao comportamento e ao desempenho animal nessas áreas, bem como à definição de coeficientes técnico-econômicos e operacionais do manejo desses sistemas, tendo o pinhão-manso como espécie arbustiva.

\section{Conclusões}

1. O sistema agrossilvipastoril (integração lavoura-pecuária-pinhão-manso) proporciona maior desenvolvimento vegetativo das plantas estabelecidas nesse consórcio.

2. O espaçamento entre plantas de $6 \times 3 \mathrm{~m}$ favorece o maior desenvolvimento vegetativo do pinhão-manso, principalmente em diâmetro de copa e número de brotações.

\section{Agradecimentos}

À Fundação de Amparo à Pesquisa do Estado de Minas Gerais (Fapemig) e à Agência Brasileira de Inovação (Finep), pelo apoio financeiro.

\section{Referências}

ACHTEN, W.M.J.; VERCHOT, L.; FRANKEN, Y.J.; MATHIJS, E.; SINGH, V.P.; AERTS, R.; MUYS, B. Jatropha bio-diesel production and use. Biomass and Bioenergy, v.32, p.1063-1084, 2008. DOI: 10.1016/j.biombioe.2008.03.003.

BEZERRA, A.A. de C.; TÁVORA, F.J.A.F.; FREIRE FILHO, F.R.; RIBEIRO, V.Q. Características de dossel e de rendimento em feijão-caupi ereto em diferentes densidades populacionais. Pesquisa Agropecuária Brasileira, v.44, p.1239-1245, 2009. DOI: 10.1590/S0100-204X2009001000005.

BIZINOTO, T.K.M.C.; OLIVEIRA, E.G. de; MARTINS, S.B.; SOUZA, S.Â. de; GOTARDO, M. Cultivo da mamoneira influenciada por diferentes populações de plantas. Bragantia, v.69, p.367-370, 2010. DOI: 10.1590/S0006-87052010000200014.

CARVALHO, E.V. de; CORRÊA DE SÁ, C.H.A.; COSTA, J. da L. da; AFFÉRRI, F.S.; SIEBENEICHLER, S.C. Densidade de plantio em duas cultivares de mamona no Sul do Tocantins. Revista Ciência Agronômica, v.41, p.387-392, 2010. DOI: 10.1590/ S1806-66902010000300010.

CHAVARRIA, G.; TOMM, G.O.; MULLER, A.; MENDONÇA, H.F.; MELLO, N.; BETTO, M.S. Índice de área foliar em canola cultivada sob variações de espaçamento e de densidade de semeadura. Ciência Rural, v.41, p.2084-2089, 2011. DOI: 10.1590/S0103-84782011001200008.

DIAS, L.A. dos S.; LEME, L.P.; LAVIOLA, B.G.; PALLINI, A.; PEREIRA, O.L.; DIAS, D.C.F.S.; CARVALHO, M.; MANFIO, C.E.; SANTOS, A.S. dos; SOUZA, L.C.A. de; OLIVEIRA, T.S. de; PRETTI, L.A. Cultivo de pinhão-manso (Jatropha curcas L.) para produção de óleo combustível. Viçosa: Ed. da UFV, 2007. 40p. 
FERREIRA, D.F. Sisvar: a computer statistical analysis system. Ciência e Agrotecnologia, v.35, p.1039-1042, 2011. DOI: 10.1590/S1413-70542011000600001.

GONZÁLEZ-SANPEDRO, M.C.; LE TOAN, T.; MORENO, J.; KERGOAT, L.; RUBIO, E. Seasonal variations of leaf area index of agricultural fields retrieved from Landsat data. Remote Sensing of Environment, v.112, p.810-824, 2008. DOI: 10.1016/j. rse.2007.06.018.

HORSCHUTZ, A.C.O.; TEIXEIRA, M.B.; ALVES, J.M.; SILVA, F.G.; SILVA, N.F. da. Crescimento e produtividade do pinhão-manso em função do espaçamento e irrigação. Revista Brasileira de Engenharia Agrícola e Ambiental, v.16, p.1093-1099, 2012. DOI: $10.1590 /$ S1415-43662012001000009.

JOSÉ, S.; GILLESPIE, A.R.; PALLARDY, S.G. Interespecific interactions in temperate agroforestry. Agroforestry Systems, v.61, p.237-255, 2004. DOI: 10.1023/B:AGFO.0000029002.85273.9b.

LEHMANN, J.; PETER, I.; STEGLICH, C.; GEBAUER, G.; HUWE, B.; ZECH, W. Below-ground interactions in dryland agroforestry. Forest Ecology and Management, v.111, p.157-169, 1998. DOI: 10.1016/S0378-1127(98)00322-3.

LEME, T.M.S.P.; PIRES, M. de F.A.; VERNEQUE, R. da S.; ALVIM, M.J.; AROEIRA, L.J.M. Comportamento de vacas mestiças Holandês x Zebu em pastagem de Brachiaria decumbens em sistema silvipastoril. Ciência e Agrotecnologia, v.29, p.668-675, 2005. DOI: 10.1590/S1413-70542005000300023.

MACDICKEN, K.G.; VERGARA, N.T. Agroforestry: classification and management. New York: John Wiley and Sons, 1990. 382p.

MÜLLER, M.D.; NOGUEIRA, G.S.; CASTRO, C.R.T. de; PACIUllO, D.S.C.; ALVES, F.F.; CASTRO, R.V.O.; FERNANDES, E.N. Economic analysis of an agrosilvipastoral system for a mountainous area in Zona da Mata Mineira, Brazil. Pesquisa Agropecuária Brasileira, v.46, p.1148-1153, 2011. DOI: 10.1590/S0100-204X2011001000005.

NEVES, C.M.N.; SILVA, M.L.N.; CURI, N.; MACEDO, R.L.G.; MOREIRA, F.M. de S.; D’ANDRÉA, A.F. Indicadores biológicos da qualidade do solo em sistema agrossilvipastoril no noroeste do Estado de Minas Gerais. Ciência e Agrotecnologia, v.33, p.105-112, 2009. DOI: 10.1590/S1413-70542009000100015.

ODHIAMBO, H.O.; ONG, C.K.; DEANS, J.D.; WILSON, J.; KHAN, A.A.H.; SPRENT, J.I. Roots, soil water and crop yield: tree crop interactions in a semi-arid agroforestry system in Kenya. Plant and Soil, v.235, p.221-233, 2001. DOI: 10.1023/A:1011959805622.

OLIVEIRA, S.J.C.; BELTRÃO, N.E. de M. Crescimento do pinhão-manso (Jatropha curcas) em função da poda e da adubação química. Revista Brasileira de Oleaginosas e Fibrosas, v.14, p.9-17, 2010.

PACIULLO, D.S.C.; CASTRO, C.R.T. de; GOMIDE, C.A. de M.; MAURICIO, R.M.; PIRES, M. de F.Á.; MÜLLER, M.D.; XAVIER, D.F. Performance of dairy heifers in a silvopastoral system. Livestock Science, v.141, p.166-172, 2011. DOI: 10.1016/j.livsci.2011.05.012.
PEREIRA, S.P.; BARTHOLO, G.F.; BALIZA, D.P.; SOBREIRA, F.M.; GUIMARAES, R.J. Crescimento, produtividade e bienalidade do cafeeiro em função do espaçamento de cultivo. Pesquisa Agropecuária Brasileira, v.46, p.152-160, 2011. DOI: 10.1590/S0100-204X2011000200006.

SALTON, J.C.; MERCANTE, F.M.; TOMAZI, M.; ZANATTA, J.A.; CONCENÇO, G.; SILVA, W.M.; RETORE, M. Integrated crop-livestock system in tropical Brazil: toward a sustainable production system. Agriculture, Ecosystems and Environment, v.1, p.70-79, 2013. DOI: 10.1016/j.agee.2013.09.023.

SATURNINO, H.M.; PACHECO, D.D.; KAKIDA, J.; TOMINAGA, N.; GONÇALVES, N.P. Cultura do pinhão-manso (Jatropha curcas L.). Informe Agropecuário, v.26, p.44-78, 2005.

SCHULZ, D.G.; FEY, R.; MALAVASI, U.C.; MALAVASI, M. de M. Crescimento de pinhão-manso em função da área útil e do consórcio com Tifton 85. Revista Floresta, v.44, p.207-216, 2014.

SEVERINO, L.S.; MORAES, C.R. de A.; GONDIN, T.M. de S.; CARDOSO, G.D.; BELTRÃO, N.E. de M. Crescimento e produtividade da mamoneira influenciada por plantio em diferentes espaçamentos entre linhas. Revista Ciência Agronômica, v.37, p.50-54, 2006.

SILVA, J.A.N.; SOUZA, C.M. de; SILVA, C.J. da; BOTTEGA, S.P. Crescimento e produção de espécies forrageiras consorciadas com pinhão-manso. Pesquisa Agropecuária Brasileira, v.47, p.769-775, 2012a. DOI: 10.1590/S0100-204X2012000600006.

SILVA, V.A.; MORAIS, D. de L.B.; KAKIDA, J.; FERREIRA, E.A.; SILVA, V. de F. Concentração do ciclo de produção de pinhão-manso por meio de podas de formação ou de produção. Pesquisa Agropecuária Brasileira, v.47, p.134-137, 2012b. DOI: 10.1590/S0100-204X2012000100018.

SINGH, B.; SINGH, K.; RAO, G.R.; CHIKARA, J.; KUMAR, D.; MISHRA, D.K.; SAIKIA, S.P.; PATHRE, U.V.; RAGHUVANSHI, N.; RAHI, T.S.; TULI, R. Agro-technology of Jatropha curcas for diverse environmental conditions in India. Biomass and Bioenergy, v.48, p.191-202, 2013. DOI: 10.1016/j. biombioe.2012.11.025.

SORATTO, R.P.; SOUZA-SCHLICK, G.D. de; SAN GIACOMO, B.M.; ZANOTTO, M.D.; FERNANDES, A.M. Espaçamento e população de plantas de mamoneira de porte baixo para colheita mecanizada. Pesquisa Agropecuária Brasileira, v.46, p.245-253, 2011. DOI: 10.1590/S0100-204X2011000300004.

SOUSA JUNIOR, J.R. de; FURTADO, G. de F.; SOUSA, J.R.M. de; LACERDA, R.R. de A.; SOUZA, A. dos S; MARACAJÁ, P.B. Consórcio de mamona com gergelim e feijão-caupi no semiárido paraibano: componentes de produção. Agropecuária Científica no Semi-Árido, v.8, p.20-28, 2012.

XAVIER, D.F.; LÉDO, F.J. da S.; PACIULLO, D.S. de C.; URQUIAGA, S.; ALVES, B.J.R.; BODDEY, R.M. Nitrogen cycling in a Brachiaria-based silvopastoral system in the Atlantic forest region of Minas Gerais, Brazil. Nutrient Cycling in Agroecosystems, v.99, p.45-62, 2014. DOI: 10.1007/ s10705-014-9617-x.

Recebido em 18 de dezembro de 2013 e aprovado em 9 de julho de 2014

Pesq. agropec. bras., Brasília, v.49, n.7, p.506-514, jul. 2014

DOI: $10.1590 / \mathrm{S} 0100-204 X 2014000700002$ 